\title{
Correction to: Research on quality improvement of the cross section cut by abrasive water jet based on secondary cutting
}

Xiaojin Miao ${ }^{1} \cdot$ Zhengrong Qiang $^{1} \cdot$ Meiping $\mathrm{Wu}^{1} \cdot$ Lei Song $\cdot$ Feng $\mathrm{Ye}^{1}$

Published online: 23 December 2019

(C) Springer-Verlag London Ltd., part of Springer Nature 2019

Correction to: The International Journal of Advanced Manufacturing Technology, Volume 97, Issue 1, pp 71-80 https://doi.org/10.1007/s00170-018-1935-8

Author Meiping Wuwmp169@jiangnan.edu.cn should also be declared as the corresponding author of the article https:// doi.org/10.1007/s00170-018-1935-8.

Publisher's note Springer Nature remains neutral with regard to jurisdictional claims in published maps and institutional affiliations.

The online version of the original article can be found at https://doi.org/ $10.1007 / \mathrm{s} 00170-018-1935-8$

\footnotetext{
Xiaojin Miao

miaoxiaojin126@126.com

Meiping $\mathrm{Wu}$

wmp169@jiangnan.edu.cn

1 School of Mechanical Engineering, Jiangnan University,

Wuxi 214122, China
} 